\title{
Studies on the radio frequency power supply system for the ITER NB injector ion source
}

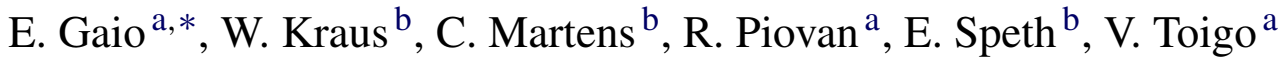 \\ ${ }^{a}$ Consorzio RFX-Associazione EURATOM-ENEA sulla Fusione, C.so Stati Uniti 4, 35127 Padova, Italy \\ b Max-Planck-Institut für Plasmaphysik, Postfach 1533, D-85740 Garching, Germany
}

\begin{abstract}
In the framework of the European activities on the ITER neutral beam (NB) injector, the design of a $1 \mathrm{MHz}, 1 \mathrm{MW}$ power supply (PS) system for the radio frequency (RF) driven ion source, has been developed in cooperation between IPP and RFX laboratories. This paper describes the studies performed with particular emphasis on the system design, the definition of the best modularity level to be adopted and the integration of the RF PS in the overall power supply system of the NB injector. Dedicated analyses were addressed to the RF matching network optimization which led to an improved and simplified solution without both matching transformers and remotely controlled variable capacitors in the source.
\end{abstract}

Keywords: ITER neutral beam injector; Radio frequency ion source; RF power supply

\section{Introduction}

For heating and current drive neutral beam injectors (NBI), ITER requires ion sources capable of delivering $40 \mathrm{~A}$ of $\mathrm{D}^{-}$ions at energy of $1 \mathrm{MeV}$ for up to $1 \mathrm{~h}$ pulses. The development of these sources was initially concentrated on filamented arc sources as described in the ITER reference design [1].

Radio frequency (RF) sources for the production of positive hydrogen ions have been successfully developed at IPP for the ASDEX Upgrade and the W7-AS

\footnotetext{
* Corresponding author.

E-mail address: elena.gaio@igi.cnr.it (E. Gaio).
}

neutral beam heating systems [2,3]. Compared to arc sources, RF sources have fewer parts, requiring just a source body, an RF coil and a matching circuit. The RF generator and the RF transmission line are much simpler than an arc power supply. RF sources are therefore cheaper and basically maintenance-free in operation due to the lack of filaments; those design features are potentially quite beneficial for ITER with its remote handling requirements.

The most recent studies on the development of a radio frequency driven negative ion source for the ITER NB injector [4], besides being aimed at demonstrating the fulfillment of the main ITER requirements, were also addressed at defining the technical specifications 
for the mechanical and electrical components. As far as the radio frequency power supply (RFPS) system is concerned, the most significant input parameters are the necessary RF power, the matching configuration, the number of the RF drivers to supply. On the basis of the input data, the RFPS design and its integration in the overall NB injector power supply system has been worked out in cooperation between IPP and RFX laboratories in the framework of the European activities on the ITER NB injector. The main results are summarized and discussed in this paper.

\section{The basic components of the RF power supply}

A schematic drawing of the basic elements of a RF power supply system is shown in Fig. 1. The load is represented by a transformer consisting of the antenna and the plasma current; therefore, the equivalent load impedance can be approximated with the antenna self inductance reduced by the mutual effect (L2) and a resistance (R2), whose value corresponds to the plasma resistance transformed according the turn ratio. With the capacitors $\mathrm{C} 1$ and $\mathrm{C} 2$, one in series the other parallel to the antenna, this resistance of a few Ohms is matched to the $50 \Omega$ impedance of the RF coaxial line. The transformer can provide both the insulation function, like in ASDEX-Upgrade [2], where the RF power supply is on ground potential and the source is on high voltage, and/or it can also be used as an additional matching element. The matching unit is connected to the RF generator by a coaxial cable.

\section{The overall power supply system of the ITER NB injectors}

In the framework of the European activities on the ITER NB injector system, a revision of the reference

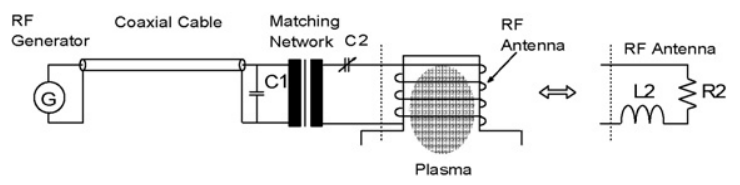

Fig. 1. Schematic drawing of the basic elements of a RF power supply system. design was first performed for the multi aperture multi grid (MAMUG) configuration of the accelerator and the arc driven ion source. Then further studies were performed to bring two alternatives, the single gap (SINGAP) accelerator [5] and the negative ion source (RF driven source), to a level of design comparable to the reference design of the MAMUG accelerator and of the arc driven source [1]. As far as the power supply system is concerned, an alternative design concept was proposed [6] and verified with respect to both the Accelerator and ion source configurations. The electric scheme of the complete power supply system referred to the SINGAP accelerator and RF driven Source is shown in Fig. 2; all the ion source power supply devices are installed inside a Faraday cage in air, named High Voltage Deck 1 (HVD1), air insulated for $-1 \mathrm{MV}$ to ground. With this solution there are no parts of the ion source power supplies referred to ground; there is just one $50 \mathrm{~Hz}, 1 \mathrm{MW},-1 \mathrm{MV}$ dc insulating transformer placed upstream of the whole system and supplying all the power supply equipment installed inside the HVD1. A first transmission line (TL1), some tens of meters long, connects HVD1 to a second High Voltage Deck named HVD2 which contains the interfaces for the cooling water and gas. A second transmission line (TL2), some meters long, connects the HVD2 to the ion source.

The integration of the RFPS system in this scheme does not present particular problems as all the ISPS devices are at the $-1 \mathrm{MV}$ potential and no additional insulation stadium is necessary. The RF generator is inside HVD1 and the RF power is transmitted by means of RF coaxial $50 \Omega$ lines placed inside the high potential conductor of the TL1 transmission line. The structure of the matching network and the location of its components are not indicated in Fig. 2; these were among the main arguments of the analyses that will be described in detail later on.

\section{The input data for the RF power supply system design of the ITER NB injector}

The main input data for the RF generator design are summarized in Table 1.

Several driver configurations have been considered at IPP [7] for experiments on RADI (half size ITER 


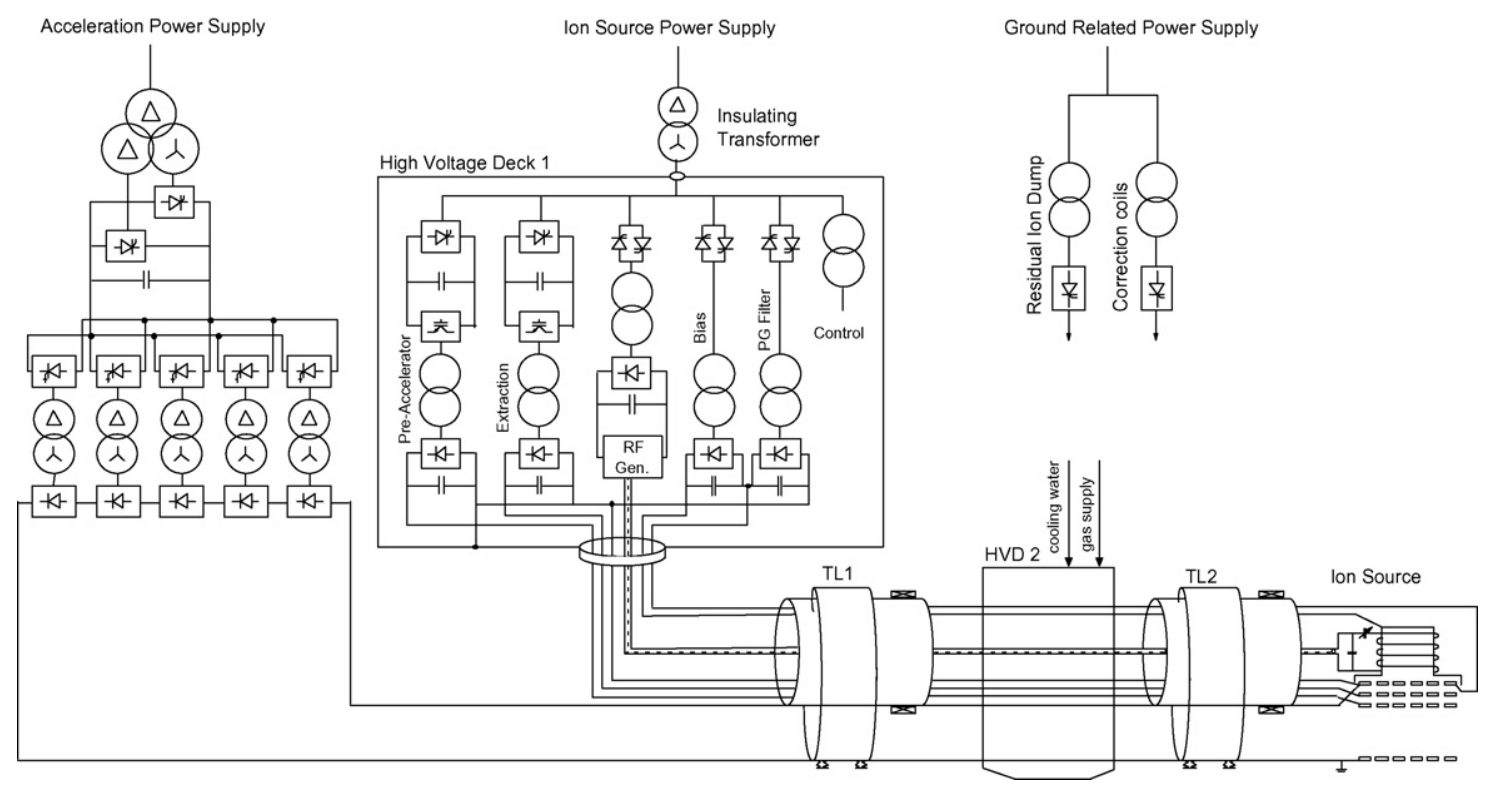

Fig. 2. The overall power supply scheme of the ITER NB injector.

source) and two driver configurations are regarded more closely. The first is composed of four circular drivers with $261 \mathrm{~mm}$ outer diameter, each pair connected in series, and the second of two rectangular drivers, as shown in Fig. $3 a$ and $b$ respectively. At present, the preferred configuration for ITER is that with the circular drivers and has been assumed for the analyses, because a smaller source with one of these drivers has met the ITER requirements concerning $\mathrm{H}^{-} / \mathrm{D}^{-}$current density [4]; anyway, the main design criteria for the power supply system remain valid for both drive configurations. A detailed description of the present mechanical design of the RF ion Source for ITER NBI is given in [8].

The antennas of both driver versions are coils of 6 turns made of water-cooled, insulated copper tubes. (a)

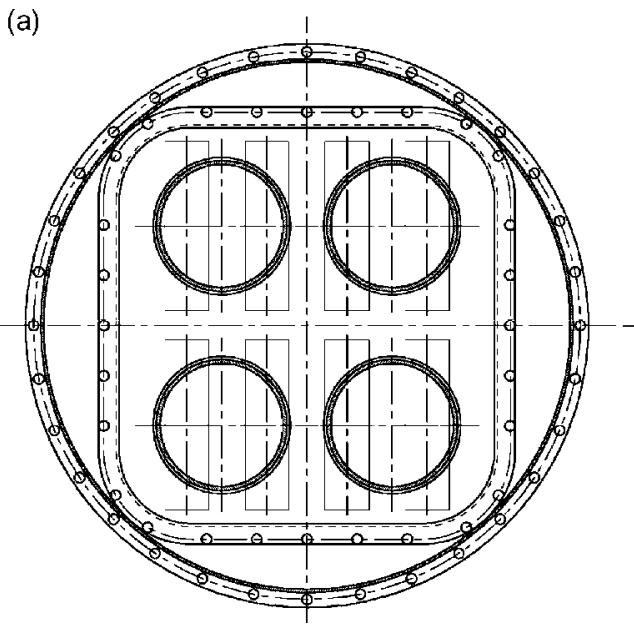

(b)

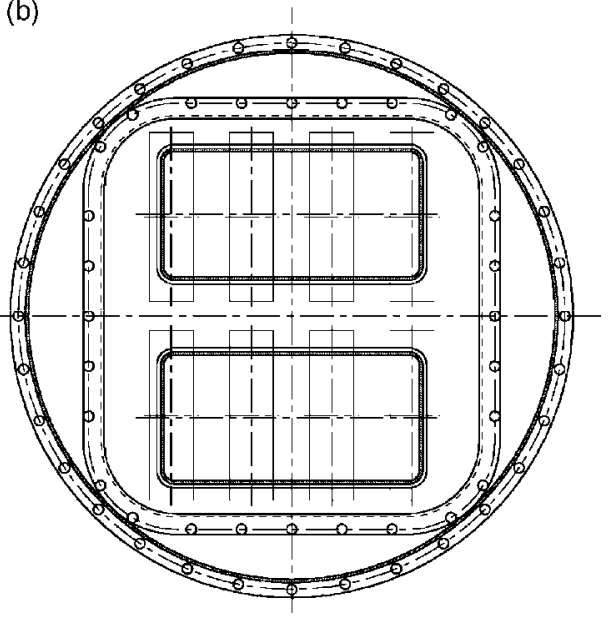

Fig. 3. (a) Four circular drivers at half size ITER source; (b) two rectangular drivers at half size ITER source. 
Table 1

Ion source power supplies-RF source

\begin{tabular}{ll}
\hline Nominal power & $1.0 \mathrm{MW}$ \\
Operating frequency & $1 \pm 0.1 \mathrm{MHz}$ \\
Load impedance & $25-75 \Omega$ \\
Rise time & $0.3-1 \mathrm{~ms}$ \\
Decay time & $<0.3 \mathrm{~ms}$ \\
\hline
\end{tabular}

Table 2

Antenna inductance

\begin{tabular}{lll}
\hline Self inductance & $\begin{array}{l}\text { Circular driver } \\
(\mu \mathrm{H})\end{array}$ & $\begin{array}{l}\text { Rectangular } \\
\text { driver }(\mu \mathrm{H})\end{array}$ \\
\hline Antenna only & 15.0 & 34.3 \\
$\begin{array}{l}\text { Antenna mounted } \\
\text { to the driver }\end{array}$ & 9.5 & 21.7 \\
\hline
\end{tabular}

The inductance values of the coils are listed in Table 2. The magnetic field of the antenna induces currents in the metallic parts of the source body, the so-called "eddy currents". The antenna behaves like a transformer with bad coupling and the eddy currents cause a reduction of the antenna inductance.

To obtain the voltage and current at the antenna some measurements have been performed at a circular driver with $261 \mathrm{~mm}$ outer diameter. Based on the results, the peak voltages at the antennas for the different driver configurations have been calculated and summarized in Table 3.

\section{The matching network}

The matching network matches the impedance of the source to the impedance of the RF coaxial line so as to assure the maximum of RF power transmission to the load.

Load impedance variations, even small, can cause the loss of the matching condition; therefore the matching network has to be adjustable so as to restore the best conditions for the power transfer to the load.

The first scheme of the matching network studied for the ITER NB injector is shown in Fig. 4 for

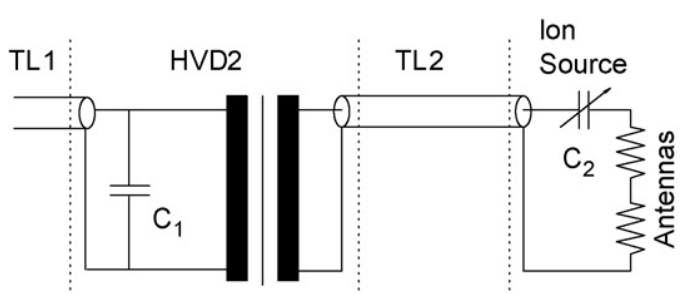

Fig. 4. Matching network of each pair of drivers.

one pair of drivers; it is composed of variable series capacitors (C2) close to the antennas, of a matching transformer and fixed parallel capacitors $(\mathrm{C} 1)$ inside the HVD2.

\subsection{Justification of the necessity to locate the capacitor C2 close to the antenna}

The presence of a variable capacitor close to the ion source represents a strong constraint; it has to be vacuum compatible and radiation resistant, but most of all, the requirement to vary the capacitance implies the installation of a remote controlled mechanical actuator inside the ion source.

On the other hand, placing the capacitor C2 close to the antenna is necessary to assures a good quality of the matching. In fact, at resonance frequency the values of the reactance of the antenna inductance and the capacitor are compensating each other and only the ohmic resistance of about $5 \Omega$ is left. This reduces the line voltage rating considerably.

If the capacitor $\mathrm{C} 2$ is moved away from the source, (for example placed in HVD2), and connected to the antenna by a transmission line (TL2), the inductive impedance at the source side is transformed to a capacitive impedance upstream of TL2. This means that the circuit cannot longer be matched by a capacitor.

\subsection{Matching network without transformer}

The scheme of Fig. 4 requires matching transformers inside the HVD2; HVD2 is a critical area too,

Table 3

Calculated voltage ratings at antenna with $85 \mathrm{~kW}$ RF power per driver

\begin{tabular}{llll}
\hline RF power $85 \mathrm{~kW}$ per driver & Circular driver $\left(\mathrm{kV}_{\text {peak }}\right)$ & Two serial connected circular drivers $\left(\mathrm{kV}_{\text {peak }}\right)$ & Rectangular driver $(\mathrm{kV}$ peak $)$ \\
\hline Total antenna voltage & 12.2 & 24.2 & 23.79 \\
Voltage between turns & 2.02 & 2.02 & 3.97 \\
\hline
\end{tabular}




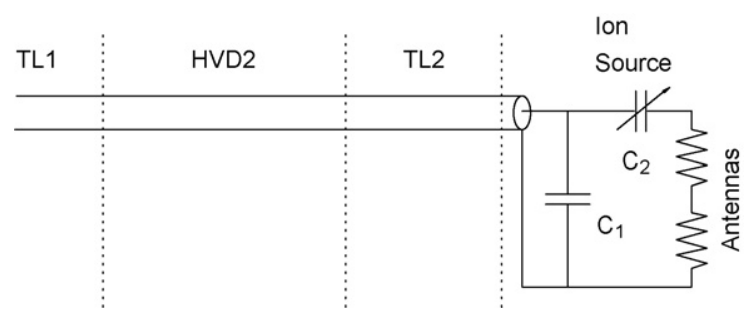

Fig. 5. Scheme of one RF line supplying two circular drivers without matching transformers in HVD2.

because it is SF6 insulated, and therefore not easily accessible, and is affected by neutron radiations. Studies have been performed to evaluate the possibility of avoiding the installation of any electric devices inside HVD2. Considering the structure of the overall power supply system (Fig. 2), which implies that the source and the RF generator are at the same voltage potential, it is in principle possible to achieve the matching conditions without matching transformer. On the basis of this consideration, a new matching network has been devised; it is shown in Fig. 5, which illustrates one line supplying a pair of drivers. This solution requires however to mount also the fix capacitor $\mathrm{C} 1$ close to the antennas.
Numerical simulations have been performed to verify the performance; Fig. 6 shows the result. The curves indicate the modulus (dotted) and the phases (continuous) of the complex impedance at the generator side $\left(\dot{Z}_{\mathrm{g}}\right)$ and at the source side $\left(\dot{\mathrm{Z}}_{\mathrm{o}}\right)$. The vertical line is the present working frequency of the RF generator; at the intersection points of the vertical line with the curves the moduli of the two complex impedances are equal to $50 \Omega$ and the phases equal to zero, thus proving that the matching condition is achievable.

\subsection{Matching by varying the generator frequency}

Once verified and confirmed the necessity of the matching capacitors close to the antennas, studies have been addressed to the possibility of avoiding at least the installation of mechanical actuators which really implies too difficult problems. Therefore, possible solutions alternative to the use of variable capacitors for adjusting the matching network have been devised.

The impedance at the end of the transmission line can be expressed as a function of the matching network parameters and of the frequency. With the previous design approach, the frequency is considered fix, the

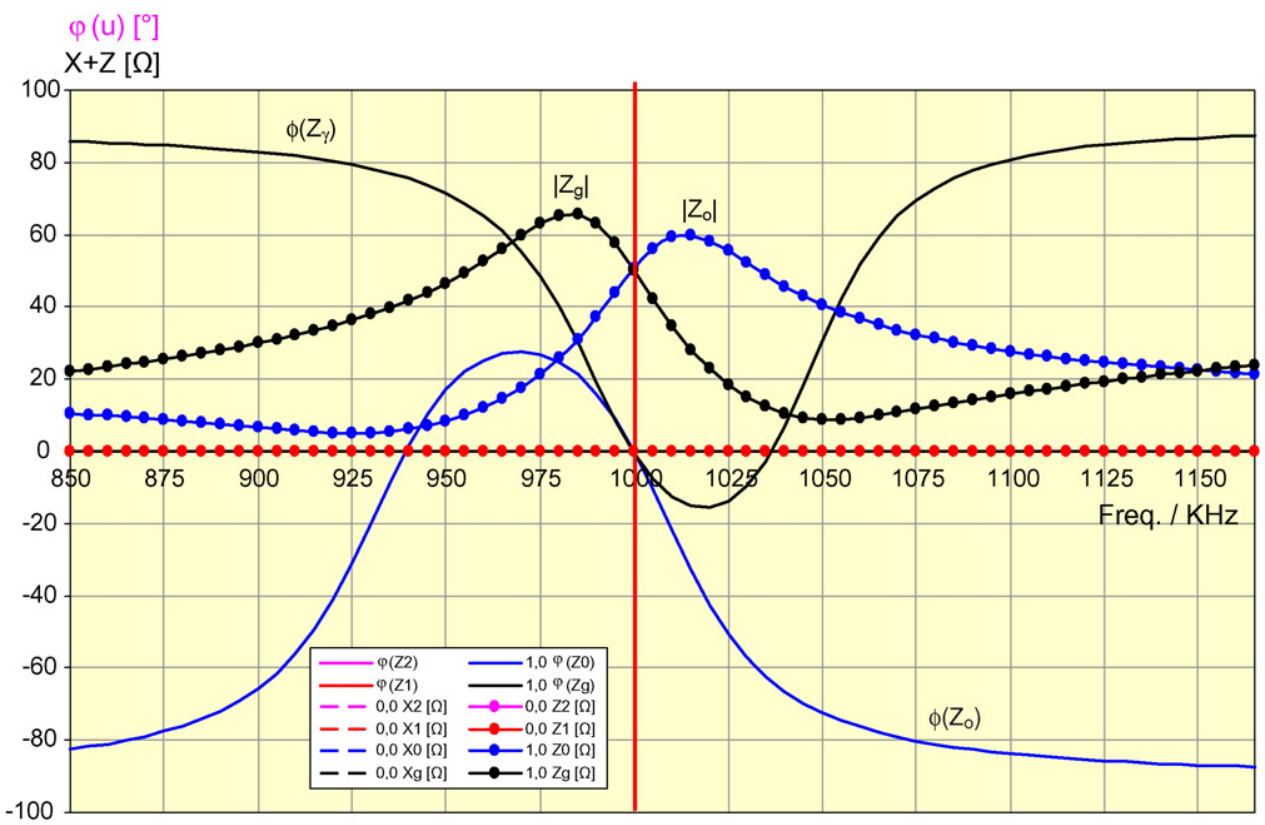

Fig. 6. Complex impedance versus frequency with optimized electrical data for RADI. 
impedance is expressed as a function of the variable capacitance and the desired variation range of the capacitance, in dependence of the load impedance variation, can be derived.

Among the alternative approaches analysed, one seems the most promising; it consists in using fix capacitors inside the ion source and in meeting the matching conditions by varying the generator frequency. In fact, once found the parameters close to the matching condition, it is possible to express the impedance at the end of the transmission line as a function of the frequency and to identify the frequency variation range which allows compensating for the expected load impedance variation.

This solution seems quite interesting as in this case the components to be adjusted, in order to modify the generator frequency, would be located in the power supply cubicles inside the HVD1, which is an area easily accessible. The calculation made showed that the required variation range of the frequency to maintain the matching condition is within $1 \%$ of the nominal frequency of $1 \mathrm{MHz}$.

\section{Modularity level-design approach}

The analyses to outline the overall RF power supply scheme were oriented toward the definition of the best modularity level to be adopted, which is related to the requirements in terms of number of RF drivers independently controlled to achieve the desired spatial uniformity of the negative ion production. The solution which will be presented in the paper was worked out with the aim of achieving the best compromise between the required performance and flexibility level, size and cost.

The basic structure of the RF generator is composed of an ac/dc input section based on an ac regulation, a step-up transformer and a diode rectifier and finally of the RF oscillator. In general the single unit approach permits optimising volumes and cost of the plant, while the modular one allows using more standard components, ensures continuity of operation in case of one unit fault and simplifies the management of spare parts. The modularity levels with the relevant advantages and drawbacks are summarized in Table 4.

\section{The final conceptual scheme of the RF power supply system for the ITER NB injector}

The solution based on one ac/dc input section, four RF generators, four lines from HVD1 and HVD2, presents the best ratio between advantages and drawbacks. The feasibility of this scheme was therefore investigated, with particular care of the possibility to supply all four oscillators from a common dc power supply.

Table 4

Configurations evaluated for the RF power supply system

\begin{tabular}{|c|c|c|}
\hline Configuration & Drawbacks & Advantages \\
\hline - One ac/dc input section & $\begin{array}{l}\text { - Detecting a possible mismatch in one network } \\
\text { requires measures in HVD2 }\end{array}$ & - Volume reduction \\
\hline $\begin{array}{l}\text { - One RF generator } \\
\text { - One line from HVD1 to HVD2 }\end{array}$ & $\begin{array}{l}\text { - The matching tuning can not be performed by } \\
\text { varying the generator frequency }\end{array}$ & \\
\hline - One ac/dc input section & $\begin{array}{l}\text { - The matching tuning can not be performed by } \\
\text { varying the generator frequency }\end{array}$ & $\begin{array}{l}\text { - One line mismatch can be identified by measures } \\
\text { installed in power supply cubicles }\end{array}$ \\
\hline $\begin{array}{l}\text { - One RF generator } \\
\text { - Four lines from HVD1 to HVD2 }\end{array}$ & - Four RF lines inside TL1 require larger space & \\
\hline $\begin{array}{l}\text { - One ac/dc input section } \\
\text { - Four RF generators } \\
\text { - Four lines from HVD1 to HVD2 }\end{array}$ & $\begin{array}{l}\text { - Larger space necessary for the RF generator } \\
\text { in the HVD1 }\end{array}$ & $\begin{array}{l}\text { - Independent power control of the different RF } \\
\text { drivers } \\
\text { - Matching network tuning can be performed by } \\
\text { varying the generator frequency }\end{array}$ \\
\hline $\begin{array}{l}\text { - Four ac/dc input section } \\
\text { - Four RF generators } \\
\text { - Four lines from HVD1 to HVD2 }\end{array}$ & $\begin{array}{l}\text { - Greater space necessary for the ac/dc Power } \\
\text { Supply in the HVD1 }\end{array}$ & $\begin{array}{l}\text { - No additional advantage with respect to the } \\
\text { previous one apart from major possibilities to } \\
\text { continue operation in case of fault }\end{array}$ \\
\hline
\end{tabular}


IPP uses self-excited free running oscillators for the RF power supply of the sources. This generator concept is simple and cheap and it adjusts itself to the best operation point by varying the working frequency within limits. In the current experiments, to supply two ITERlike drivers in series, self-excited oscillators with two tetrodes in push-pull arrangement are in operation; the nominal power is $180 \mathrm{~kW}(\mathrm{cw})$, the operation frequency $1 \mathrm{MHz}$.

A peculiar feature of these RF oscillators is that the power regulation is not achieved via the variation of the anode voltage but via the screen grid of the tetrodes. Hence the anode voltage is constant and identical to all four generators and can be supplied by a single dc power supply.

As a consequence, the design approach described above can be adopted with these types of generators; the resulting conceptual scheme is shown in Fig. 7.

Four RF lines are necessary; coaxial cables with $\mathrm{PE}$ insulation between inner and outer conductors are not suitable in the $1 \mathrm{MHz} \mathrm{RF}$ power range above $60 \mathrm{~kW}$ and continuous operation. For this conditions so called "rigid lines" are suitable, with inner and outer conductors made of a bare copper tube. As a first approximation, the size of $3.125 \mathrm{in}$. and a rating power of $500 \mathrm{~kW}$ seem adequate and also such that the four RF lines can be hosted within the area of central conductor of the TL1 and TL2 lines of the present design, including the cooling, if necessary.

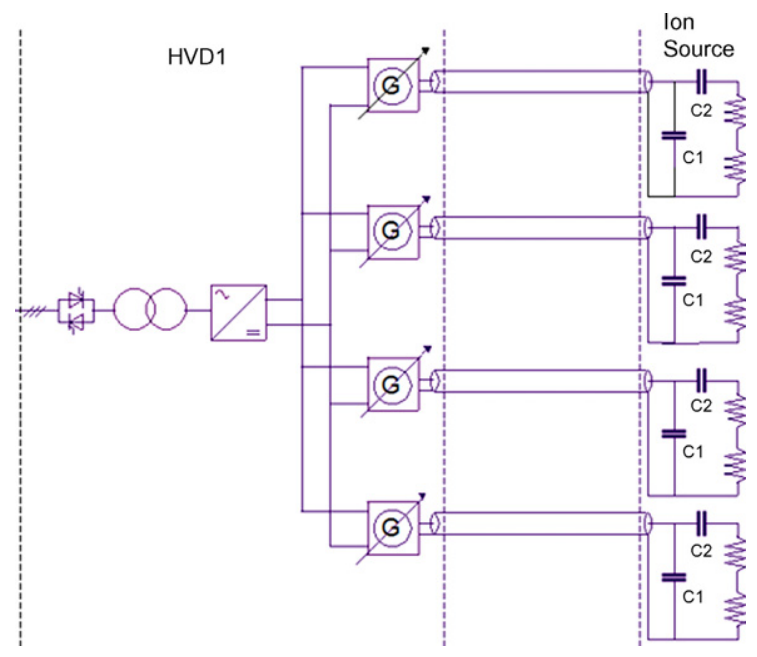

Fig. 7. The overall RF power supply scheme.

\section{Conclusions}

A conceptual design has been achieved for the power supply system of the RF source for ITER NB injector. The source is assumed to be a modular device with eight individual drivers arranged in four pairs, each fed by a common RF generator independently controlled. A single ac/dc input stage feeds the four generators. This solution allows the flexibility level necessary to achieve the desired spatial uniformity of the negative ion production while assuring a reasonable design in terms of feasibility, size and cost. A new matching network structure has been devised, just based on fixed capacitors inside the ion source and the adjustment performed by varying the RF generator frequency. The important achievement of this design is the possibility of avoiding mechanical actuators inside the ion source and of any electric devices inside the HVD2. Dedicated experiments to verify basic assumptions are under way.

\section{Acknowledgment}

This work, supported by the European Communities under the contract of Association between EURATOM/ENEA, was carried out within the framework the European Fusion Development Agreement. The views and opinions expressed herein do not necessarily reflect those of the European Commission.

\section{References}

[1] ITER technical basis, IAEA, Vienna 2002, ITER EDA, Doc. Series N. 24, Plant Description Document, Sec. 2.5.1.

[2] W. Kraus, J.H. Feist, E. Speth, R. Wihelm, A high power RF plasma source for Asdex-Upgrade Neutral Beam Injection, Fusion Technol. (1994) 473-476.

[3] W. Kraus, P. Franzen, B. Heinemann, E. Speth, O. Volmer, Recent developments of long pulse RF ion sources for NBI systems, Fusion Eng. Des. 56-57 (2001) 499-503.

[4] E. Speth, H.D. Falter, P. Franzen, U. Fantz, M. Bandyopadhyay, S. Christ, et al., Overview of the RF source development, Nucl. Fusion 46 (6 (June)) (2006) 220-238.

[5] H.P.L. de Esch, R.S. Hemsworth, P. Massmann, Singap: the European concept for negative ion acceleration in the ITER neutral injectors, Rev. Sci. Instrum. 73 (2) (2002) 10451047. 
[6] E. Gaio, V. Toigo, A. De Lorenzi, R. Piovan, L. Zanotto, The alternative design concept for the ion source power supply of ITER neutral beam test bed and first injector, Fusion Eng. Des., in press, doi:10.1016/j.fusengdes.2007.04.013 (regular issue).

[7] W. Kraus, B. Heinemann, H.D. Falter, P. Franzen, E. Speth, A. Entscheva, et al., RF-source development for ITER: Large area $\mathrm{H}^{-}$beam extraction, modifications for long pulse operation and design of a half size ITER source, Fusion Eng. Des. 74, Part A (2005) 337-341.

[8] D. Marcuzzi, P. Agostinetti, M. Dalla Palma, H.D. Falter, B. Heinemann, R. Riedl, Design of the RF ion source for the ITER NBI, in: 24th SOFT Conference, Warsaw, Polland. September, 2006. 